\title{
DE SABIOS A PUBLICISTAS
}

\author{
Carlos Ossandón Buljevic
}




\section{CARLOS OSSANDÓN BULJEVIC}

Profesor de Estado en Filosofía titulado en la Pontificia Universidad Católica de Chile y Doctor en Filosofía graduado en la Universidad de Gante, Bélgica. En la actualidad es miembro del Consejo Académico del Magíster en Comunicación Política del ICEI y de los claustros académicos del Doctorado en Estudios Latinoamericanos, del Doctorado en Ciencias Sociales y del Doctorado en Filosofía de la Universidad de Chile. 


\section{DE SABIOS A PUBLICISTAS ${ }^{2 *}$}

Si desde hace solo algo más de un siglo unos sujetos han comenzado a ser reconocidos por el sustantivo o el nombre común de "intelectuales", el problema de las relaciones entre estos y la sociedad tiene una larga historia y muestra importantes aristas. Es lo que nos recuerda Norberto Bobbio (1998). Desde la concepción platónica que buscó reunir al rey y al filósofo, a la política y a la filosofía, mucha agua ha corrido bajo el puente o son muy diversos los tópicos que estas relaciones han venido arrastrando.

La voz es, sin embargo, más o menos reciente. Es sabido que ella adquiere carta de ciudadanía en el contexto del "Yo acuso" de Émile Zola, documento hecho circular en el diario L'Aurore en 1898 con ocasión del affaire Dreyfus.

Desde aquel célebre manifiesto los estudios sobre "intelectuales" se han multiplicado y también tecnificado. Se ha indagado sobre los límites máximos y mínimos que soporta el término, sobre las distintas modalidades y funciones de estos, sobre su mayor o menor "autonomía", sobre sus posiciones y conflictos en los "campos intelectuales", sobre sus relaciones con los distintos poderes y las clases sociales, sobre su (no) lugar en la cultura de masas o en los actuales escenarios de la globalización. Las propuestas de Max Weber, Antonio Gramsci o Pierre Bourdieu han permitido el desarrollo de distintas tradiciones o enfoques. También en América Latina, autores como Ángel Rama, Arturo Andrés Roig, José Joaquín Brunner, Beatriz Sarlo o Julio Ramos han entregado contribuciones importantes en estos dominios.

Si bien lo que desarrollaré a continuación se enmarca o se inspira en ciertos aspectos desarrollados por algunas de las perspectivas mencionadas, el presente artículo se mueve en un terreno bastante circunscrito: tiene como soporte unas acciones o gestos escriturales que se dan en la prensa chilena de la segunda mitad del siglo XIX. El propósito es precisar allí unas relaciones que perfilan un muy singular modo de validación o de posicionamiento intelectual. Al hacerlo, me abriga la convicción que en materiales aparentemente triviales, cotidianos, por definición

2. * El presente artículo apoya, precisa y amplía brevemente algunos de los tópicos que desarrollé en el libro: El crepúsculo de los sabios y la irrupción de los publicistas (1998). 
desechables ${ }^{3}$, se han articulado una diversidad de perfiles o maneras de ejercer el oficio intelectual, no siempre nítidos ni estables.

En el marco descrito, y atendiendo especialmente las relaciones que se dan en la prensa entre las letras y los poderes, me interesa describir someramente ciertos gestos de "emancipación" o de "corrimiento" que se observan en estas relaciones y que terminan por desplazar (parcialmente) una figura que había manifestado una acendrada voluntad institucional y fundadora: me refiero al "sabio" decimonónico. Bajo esta figura se activaron o se ampararon distintos actores que, bajo una impronta básicamente ilustrada, ofrecieron perfiles más o menos republicanos, más o menos liberales, más o menos eclécticos, tales como Juan Egaña, José Joaquín de Mora o Andrés Bello. Sin menoscabo de sus diferencias, estos actores comparten algunos de los siguientes rasgos: saber enciclopédico, vocación por sentar bases, voluntad realizadora, espíritu sistematizador y proyectual, práctica poligráfica, interés por lo jurídico o lo constitucional, por la educación y, muy particularmente en Andrés Bello, por la gramática. Es en el periódico El Araucano, en las exterioridades que ostenta su cuerpo, en su estructura pareja y estable, en su escritura fría y atenida al "bien decir", o en las responsabilidades institucionales u organizativas que se echa encima, donde se hace particularmente visible esta figura.

En diálogo o contraste más bien con esta figura, nos podemos preguntar en la perspectiva que nos interesa y sin pretender el señalamiento global de un "período" de la historia cultural o periodística chilena: ¿se asiste en la prensa -en ciertos cercos o espacios comunicacionales específicos de la segunda mitad del siglo XIX, más biena la emergencia de unos lugares y operaciones discursivas que hacen perder terreno o centralidad a la figura del "sabio"? ¿En qué momento y, sobre todo, bajo qué particulares condiciones se comienza a romper la unidad entre escritura y voluntad institucional? ¿A partir de qué nuevas disposiciones y en vínculo con qué referentes se reconocen determinadas subjetividades tras el debilitamiento que experimenta el complejo engranaje estratégico-fundacional? $\mathrm{O}$ ¿qué nuevas modulaciones toma

3. Según Nietzsche, el periódico y su lectura son apenas un "medio específico de consuelo", que disipa o adormece los estremecimientos o riesgos que supone una cultura o una experiencia que, por el contrario, se nutre o remueve los grandes problemas de la existencia. Este "medio" sería abiertamente agresivo contra un espíritu que, en su "inactualidad", no mantiene ninguna sintonía con las jergas, estéticas o articulaciones de un periodismo que por naturaleza domestica el horror y empobrece la afección. Friedrich Nietzsche, Sobre el porvenir de nuestras escuelas, Barcelona, 2000, pp. 57, 58, 175. Según Andrés Sánchez Pascual (prologuista y traductor de Nietzsche), "la 'lectura de periódicos' fue un tema tocado por Nietzsche desde muy temprano, y siempre en sentido negativo [...] En más de una ocasión compara esa costumbre a la 'diaria visita a la cervecería', y dice que es un sustitutivo de las 'oraciones diarias”, en Friedrich Nietzsche, Más allá del bien y del mal, 1994, nota 5, p. 262. 
la intelligentz̨ia decimonónica en Chile, más allá del pathos o del prestigio del letrado que se reconocía en una relación estrecha -aunque muy matizada o compleja en ciertos casos- con la construcción de una racionalidad que buscaba correlacionar la gramática con el código civil, por ejemplo, en tareas específicamente inaugurales u organizativas?4

Buscando seguir la genealogía de la voluntad de "desprendimiento" de las relaciones institucionales, aunque no siempre puramente instrumentales, entre cultura y poder, y más allá de cortes que no dejan nada detrás de sí después de sus pretendidos colapsos, o de irrupciones adánicas sin antecedentes previos, nos topamos con una figura distinta a la del "sabio". El resquebrajamiento que comienza a experimentar el modelo del intelectual fundador, o la inicial y relativa disolución de un modo de validación intelectual ligado al diseño del país, permite la irrupción en la prensa del período de una figura que poco se había visto en la primera fracción del XIX: se trata del "publicista", una modalidad que exhibe nuevos lugares de enunciación y recursos discursivos, interesada en proporcionar información y sobre todo en hacer circular "juicios" sobre los asuntos de interés público, contribuyendo así a desarrollar un foro político activo, una "opinión pública", ciertamente restringida o selectiva 5 .

Examinemos brevemente las condiciones periodísticas que permiten la emergencia de la figura que nos ocupa. Se podría decir que con la prensa liberal de los hermanos Justo y Domingo Arteaga Alemparte (La Semana, 1859-1860; La Libertad, 1866-1871; Los Tiempos, 1877-1882), se abren más nítidamente las posibilidades para que esta tome consciencia de sí, acceda a una cierta "autonomía" (siempre problemática y relativa) o salga de esa "minoría de edad" que en otro contexto señaló Kant ${ }^{6}$. Esta prensa establece nuevos plexos estructurales con el

4. Ángel Rama (La ciudad letrada, 2004) señala que en la segunda mitad del siglo XIX y en el terreno de la prensa, precisamente, se abren para las funciones intelectuales unos espacios más libres o menos dependientes de las tareas encomendadas por el poder estatal.

5. Por "publicista" no habría que leer "propagandista". La primera fue una voz relativamente corriente en el siglo XIX: el "publicista” José Victorino Lastarria, por ejemplo. Esto no significa que todo Lastarria-autor se condense en esta función. Cuando este participó en El Timón, periódico que tenía el propósito de combatir a El Corsario, donde fue tratado de "huacho, roto, pícaro" (Cfr. Revista Chilena, 1917), Lastarria lo hizo más bien en tanto ese sujeto ocasional e instrumental característico de la prensa de "barricada". Sobre el espacio liberal-burgués al cual se adscribe la figura del "publicista", ver Jürgen Habermas, Historia y crítica de la opinión pública. La transformación estructural de la vida pública, 1994. Esta obra ha constituido una de mis más importantes fuentes de inspiración.

6. Es precisamente Justo Arteaga Alemparte y sus largos artículos sobre el diarismo en la América española, publicados en La Semana, quien mejor administra con su lenguaje esta representación. 
poder político, muestra un espaciamiento de mayor desarrollo y peso formal, y queda en mejores condiciones para producir o distribuir significaciones propias. Sin considerar toda la variedad del espectro periodístico del período, se puede identificar ahora, más claramente que en anteriores paisajes, un nuevo tejido comunicacional que se expresa en un tipo de prensa "independiente", informativa y "raciocinante", que no se agota ciertamente en los periódicos que acabamos de citar (La Época, 1881-1892, por ejemplo, es uno de los tantos diarios que habría que mencionar). Este nuevo tejido da cuenta de un posicionamiento que supone la distinción hegeliana entre la esfera estatal y la de la sociedad, la activación y el afincamiento en esta última, y el esfuerzo de constitución o desarrollo de una "publicidad" política y crítica capaz de mediar entre estas dos esferas y de conectar argumental y libremente a las voluntades (Habermas, 1994).

Este nuevo tejido, que se confunde con un tipo de prensa privada y definida por su propia capacidad de "significación" e intervención en el ámbito público, tiene como característica básica la sustitución, o al menos la pérdida de vigor, de aquellas funciones que legitimaban otras publicaciones periódicas. En particular, la proclama o el llamamiento (v.gr. La Asamblea Constituyente, 1858), la exposición doctrinaria (v. gr. La Revista Católica, 1843-1874); la defensa o el ataque ad hominen de las posiciones políticas (v.gr. El Hambriento, 1827 y El Canalla, 1828), la constitución adánica de referentes literarios (v.gr. la Revista de Valparaíso, 1842), la necesidad de ilustrar o propagar conocimientos nuevos (v.gr. El Museo de ambas Américas, 1842) y el desarrollo de una perspectiva preferentemente estatal-fundacional (v.gr. El Araucano, 1830-1877).

Reemplazando parcialmente estas funciones, y a partir de su propio espaciamiento u organización textual, la nueva prensa que destacamos hace valer unos artefactos (la información, el raciocinio, la discusión, la reproducción de noticias y opiniones de otros medios) y unos objetivos (la autonomía de la esfera social y la regulación de la sociedad civil y política) que de hecho fracturan una relación más o menos "simbiótica", ya sea con intereses circunstanciales o particulares (partidos o grupos políticos, por ejemplo), ya sea con los más "universales" de un Estado que había que construir o consolidar. En estos periódicos, la escritura opinante se vuelca más hacia aspectos relativos a la "regulación" o reforma de la sociedad civil y política, contribuyendo a la constitución o desarrollo de una esfera crítica y pública, que a la instauración de unas bases o de unas "gramáticas" tendientes a habilitar y disciplinar al nuevo sujeto republicano.

Dentro de esta nueva prensa, agreguemos que La Libertad y Los Tiempos, que incorporan los elementos comerciales, de servicios y noticiosos que habían inaugurado periódicos como El Mercurio de Valparaíso (1827) o El Ferrocarril de Santiago (1855-1911), tienen como correlato la emergencia de un público más 
amplio y heterogéneo que el público básicamente "ilustrado" o "literario" de La Semana. Mientras esta última decide suspender temporalmente su publicación entre el 7 de enero y el 3 de marzo de 1860, aduciendo "la emigración al campo de la mayor parte de nuestra sociedad", los periódicos La Libertad y Los Tiempos, si bien incluyen aquellos que emigran al campo en el período de la canícula, sus páginas se dirigen más ampliamente hacia todos aquellos que saben leer y que desean estar informados o participar en las distintas modulaciones de la vida pública.

La nueva prensa se constituye ante o frente la esfera gubernamental y estatal (cuestión que, a pesar de dirigirse a un público restringido, capta auroralmente $\mathrm{La}$ Semana). Desde este posicionamiento (ya no desde o al lado del Estado-razón) enseña unas realidades (propias de una sociedad civil en desarrollo) y expresa unas opiniones que buscan incidir en aspectos relativos a la administración, buen funcionamiento o reforma del país. Es precisamente en este nuevo espacio comunicacional por donde se abre paso la figura del "publicista": una modalidad cuya especificidad, como ya adelantábamos, se juega en la relación que establece entre sus propios productos escriturales y la circulación o proyección de estos en una esfera de intermediación definida por el interés público y en la cual concurren y discuten distintas voces del entramado social y político.

Como "sujeto enunciativo", más que como instancia productora individual, el "publicista" discurre desigualmente por "autores" y periódicos que son distintos entre sí. Se pueden destacar, sin embargo, algunos nombres. Bajo esta modalidad enunciativa, además de Justo Arteaga Alemparte y José Victorino Lastarria ya mencionados, destacan escritores tales como Zorobabel Rodríguez, Fanor Velasco o Manuel Blanco Cuartín 7 . Al igual que Arteaga y Lastarria, estos últimos poseen una personalidad intelectual que exhibe constelaciones o temples propios. En especial, Zorobabel Rodríguez: un católico liberal, discípulo de Courcelle Seneuil, que realiza - según Sofía Correa S. (1997) - un serio esfuerzo de reelaboración y armonía entre Adam Smith, John Stuart Mill, Herbert Spencer y el dogma católico. Estos "publicistas" intervienen en la arena pública desde un "otro" lugar, privado o construido por ellos mismos. Ese otro lugar evita su disolución sin más en lo público o en la política.

Esta nueva figura no se confunde con el "reporter" que se consolida con el desarrollo del telégrafo (que comienza a operar desde 1851) y de otras modernizaciones, ni se identifica del todo con el modelo propiamente iluminista o doctrinario como tampoco con el escritor "ex-céntrico" o modernista de fines del XIX; exhibe una voluntad menos formalizadora y disciplinante que la del

7. Cfr. Raúl Silva Castro, Prensa y periodismo en Chile (1812-1950), 1958. 
"sabio" fundador, no se reconoce tampoco en esa función puramente instrumental y ocasional del sujeto de una prensa de "barricada", ni se activa en función de requerimientos específicos asociados a nuevos actores sociales o políticos (como será más adelante la prensa de Luis Emilio Racabarren). Tiene sí una vocación más pública o periodística que el "literato" de la generación de 1842.

El desarrollo, desde la esfera privada, de una red de periódicos más vasta, diversa e interconectada, y también de más amplias tiradas, que la que se dio en la primera mitad del XIX; la instalación del ciclo completo de la "industria impresora" (Subercaseaux, 1993); el gradual/lento acrecentamiento y diversificación de los lectores o la paulatina incorporación de nuevos sectores sociales a la producción y al consumo cultural (es ilustrativa en esta dirección la prensa satírica de Juan Rafael Allende, los periódicos obreros o los vinculados al Partido Democrático, la prensa de provincias, etc.), así como la inicial constitución de un mercado de bienes culturales y de la información, que comienza a hacer valer sus propias demandas, constituyen el entramado social y comunicacional dentro del cual se desenvuelve, estimula o posibilita la figura que aquí estamos destacando.

Si bien no hay que perder de vista que el "publicista" y la prensa que lo sostiene aparece siempre bajo los efectos de una mayor o menor saturación ideológica y política, esta figura consagra con todo la distinción entre los que hacen política (aunque él también la haga) y los que emiten y crean "opinión pública", anclando en esta nueva apariencia general su identidad más característica. Su ámbito de legitimación no es así el de la política partidista principalmente, sino el de los hombres "libres" y opinantes; no es el "golpe" de cátedra, ni la opción voluntarista por uno de los grupos políticos en pugna, sino la capacidad comunicativa o interpeladora del "raciocinio" político; no es tampoco lo público (estatal) sino el público.

Lejos de la ritualidad y del halo de atemporalidad que ostentan los grandes proyectos históricos, el "publicista" es básicamente un creador y abastecedor de bienes culturales fungibles, de suministros perecederos capaces de circular por una esfera social contradictoria o conflictual y de alimentar o dar cuerpo a una "publicidad" política activa y crítica, aunque no suficientemente advertida de sus límites o ficcionalizaciones.

$$
* * *
$$

Para terminar, unos breves alcances sobre la prensa periódica como objeto de estudio. Sobre ella han circulado distintos conceptos o aproximaciones. Ya he recordado que, para Nietzsche, la prensa es, a falta de densidad cultural y existencial, apenas un "consuelo" o un sustituto de las "oraciones diarias". Ha sido definida 
también como "literatura bajo presión": un tipo de escritura que bajo el efecto de distintas presiones (las del editor, las del tiempo, las del formato y la extensión o las del público lector) permite complejas combinaciones en ciertos casos, por ejemplo en crónicas que se alimentan tanto de criterios periodísticos y factuales como literarios y subjetivos (Susana Rotker, 1991). En otra parte señalé que la prensa periódica se proyecta a su vez como un cierto "mapa" o campo visual y temporal, que suponemos indispensable como instrumento de orientación en el contexto de la ciudad, su vida y sus "servicios". Desde esta perspectiva, el periódico enseña una "diferencia específica" que no se disuelve ni es simple "reflejo" de una "realidad" que, supuestamente instalada a sus espaldas, lo determina sin más. Como todo "mapa" -salvo aquel imaginado por Jorge Luis Borges- no es ni se confunde con su territorio, lo que no significa que este se construya sobre el vacío o al modo de una creación divina ex nibilo (Ossandón, 2005). Para Julio Ramos, por otra parte, el periódico es aquella articulación que permite "pensar la ciudad" -y el país, agregocomo un espacio social coherente, desde una lógica paradójicamente fragmentaria (2003).

Cualquiera que sea la mirada que se adopte sobre la prensa, como condición para "pensar la ciudad" (que hoy bajo nuevos formatos y operaciones no es exclusiva de la prensa), como "mapa" o "guía", como estrechamiento de la experiencia o "consuelo", o como "literatura bajo presión", lo cierto es que ella es siempre algo más que un "medio": el espacio sin más de las noticias o comentarios del día, o el escueto "goteo uniforme de tinta", como señaló Stéphane Mallarmé (según lo recuerda Jacques Rancière). Y esto porque ella es sobre todo un espacio de relación e interconexión de mensajes y códigos, de combinación, selección y jerarquización de signos, tal como lo señaló hace ya tiempo Eliseo Verón. Por estos espacios se construyen unas secciones o particiones del mundo, unas actualidades, unos sentidos comunes, unas maneras de experimentar la aceleración del tiempo, unas hegemonías y también unas contra hegemonías culturales. La prensa es, en suma, o antes que nada, un espacio de "significación", de construcción (y también de descarte) de mundo, que define lo que hay que atender o prestar atención, y no obviamente mera superficie de proyección de unas realidades "naturalmente" dadas. Por estos espacios (no inertes ni en "grado cero", diría Barthes) circulan y se combinan distintas "series visuales" (ver nuevamente Verón, 1969) y también, como parte de ellas, unas escrituras, unas autoridades discursivas o unas "modalidades de enunciación", que puede ser provechoso atender en su diversidad, pluralidad y vínculos con otras prácticas, si el propósito es identificar o precisar determinados modos de ser intelectual. Es lo que he intentado hacer en este artículo, subrayando la emergencia de una figura crítica y pública a la vez, la del "publicista" decimonónico, hoy bastante deslavada, y que puede ser un insumo más en el examen de las 
ausencias-presencias que constituyen el mundo que nos toca vivir. Cuando hoy algunos nos hacen creer que no tiene mayor sentido publicar artículos que no arrojen "puntajes" para la "carrera" académica, profundizando en la distancia que se ha venido dando en relación con preocupaciones más generales o públicas, es siempre oxigenante tener a la vista una variedad de modos de validación, de intervención o de posicionamiento de los intelectuales. 


\section{REFERENCIAS}

Roland Barthes, El grado cero de la escritura, México, Siglo XXI, 2009.

Norberto Bobbio / Michelangelo Bovero, Sociedady Estado en la filosofía moderna.

El modelo iusnaturalista y el modelo hegeliano-marxiano, México, Fondo de Cultura Económica, 1986.

Norberto Bobbio, La duda y la elección. Intelectuales y poder en la sociedad contemporánea, España, Paidós, 1998.

Ramón Briseño, Cuadro sinóptico periodístico completo de los diarios y periódicos en Chile publicados desde 1812 hasta el año de 1884. Reedición de Guillermo Martínez y Raymond Colle. Pontificia Universidad Católica de Chile, Centro de Estudios de la Prensa, 1987.

José Joaquín Brunner / Ángel Flisfich, Los intelectuales y las instituciones de la cultura, Chile, Ediciones UDP, 2014.

Sofía Correa, “Zorobabel Rodríguez, católico liberal”, en Estudios Públicos, Chile, n. 66, otoño, 1997.

"Diario de don José Victorino Lastarria, desde junio de 1849 hasta marzo de 1854", en Revista Chilena, Tomo I, Santiago, 1917.

Michel Foucault, L'archéologie du savoir, France, Éditions Gallimard, 2004.

Jürgen Habermas, Historia y crítica de la opinión pública. La transformación estructural de la vida pública, Barcelona, Ediciones G. Gili, 4ª edición, 1994.

Emmanuel Kant, “¿Qué es la Ilustración?”, en Filosofía de la historia, México, Fondo de Cultura Económica, 1987.

Friedrich Nietzsche, Sobre el porvenir de nuestras escuelas, Barcelona, Tusquets Editores, 2000.

Friedrich Nietzsche, Más allá del bien y del mal, Madrid, Alianza Editorial, 1994.

Carlos Ossandón B., El crepúsculo de los sabios y la irrupción de los publicistas, Chile, LOM-Arcis, 1998.

Carlos Ossandón B. / Eduardo Santa Cruz A., El estallido de las formas. Chile en los albores de la "cultura de masas", Chile, LOM-Arcis, 2005.

Ángel Rama, La ciudad letrada, Santiago, Tajamar Ediciones, 2004.

Julio Ramos, Desencuentros de la modernidad en América Latina. Literatura y politica en el siglo XIX, México, Fondo de Cultura Económica, 2003. 
Raúl Silva Castro, Prensa y periodismo en Chile (1812-1950), Santiago, Ediciones de la Universidad de Chile, 1958.

Bernardo Subercaseaux, Historia del libro en Chile (alma y cuerpo), Santiago, Editorial Andrés Bello, 1993.

Susana Rotker, Fundación de una escritura. Las crónicas de José Martí, Cuba, Casa de las Américas, 1991.

Eliseo Verón, "Ideología y comunicación de masas: la semantización de la violencia política", en Varios autores, Lenguaje y comunicación social, Buenos Aires, Ediciones Nueva Visión, 1969. 